\title{
Focus Factors: Exploring Cross-Cultural Business Dynamics Of Making Deals And Building Relationships In India
}

Andrew H. Clem, Nova Southeastern University, USA

Bahaudin G. Mujtaba, Nova Southeastern University, USA

\begin{abstract}
The world houses a grand spectrum of people and cultures constantly changing and renewing themselves. Some of these peoples are historic and rich with culture, while others are relatively new in history and evolving every day. These cultures are not self-reliant, nor are they selfcommunicating. Spread out across every continent, the various cultures and countries of the world are morphing and forming relationships at a rate faster than ever before. As technology continues to flourish, markets and economies continue to become intertwined as well. Cultures and business practices are often vastly different. A serious effort from global business leadership needs to be placed on learning about culture as business deals are formed and negotiated. India is an Asian country containing both a rich history, as well as an extremely significant presence in the current global economy. By presenting a general overview of India, a progressive look at more focused concepts can then be explored. Concepts, such a global cross-cultural leadership, can be looked into as well as how cultures compare and contrast to the business behaviors within India. Furthermore, a broad overview of Geert Hofstede's research on India is explored for reflection and application. One of the more important focus factors that will be displayed is how negotiation plays into inter-cultural business dealing with India. By focusing on cross-cultural leadership and behavioral dynamics of Indian culture, a greater chance of success in relationship-building and business partnership opportunities can be solidified.
\end{abstract}

Keywords: Deal-focused; relationship-focused; culture; India

\section{INTRODUCTION}

C ndia is truly rich in culture and has engrained, within itself, a very dynamic history. Though it did not become an independent country until 1947, it has thousands of years worth of independent cultural growth (GlobalEdge, 2009, India). Though its ethnic groups are by majority Hindus and Muslims, India has an extremely wide range of cultural diversity just within itself. India has been described as "a complex multicultural country of 500,000 villages, with 17 major languages and 22,000 dialects and numerous religions" (Gesteland, 2005, p. 129). When population and other factors enter into the cultural picture, the complexity can be seen further by looking at Figure 1.

Figure 1: Indian Demographic Data

(GlobalEdge, 2009, India; (Kwintessential, 2010, India)

\begin{tabular}{|l|l|}
\hline Population & 1.16 billion (2009 est.) \\
\hline Labor Force & 467 million (2009 est.) \\
\hline Ethnic Groups & Indo-Aryan, Dravidian, Mongoloid, Other \\
\hline Religions & Hindu, Muslim, Christian, Sikh, Buddhist, Jain, Parsi, Other, Unspecified \\
\hline Languages & $\begin{array}{l}\text { Bengali, Telugu, Marathi, Tamil, Urdu, Gujarati, Malayalam, Kannada, Oriya, Punjabi, Assamese, } \\
\text { Kashmiri, Sindhi, Sanskrit, Hindustani, Other }\end{array}$ \\
\hline
\end{tabular}


Often geographically, cultures will vary fairly significantly, though they may still share a similar set of values and customs. Over time, and propelled through its independence, India has become a major world leader in business. All of these cultural variances, though, are housed within its government.

The Indian government is what is classified as a federal republic, but is more specified by its Constitution as a "sovereign socialist secular democratic republic" (India.gov.in, 2005). Since it is a federal system, it is similar to that of the United States. However, its real difference lies within its structure, which is a Parliamentary system. The Parliamentary form of government actually lies closer to how the British government system is set up.

The Indian federal government has an elected president and vice president. Dissimilar to the United States, however, the vice president does not become president "following the death or removal from office" (GlobalEdge, 2010, India). Dividing the power up, the Indian Parliament is divided into two Houses - the Council of States and the House of the People. In contrast to the United States, the executive power does not lie with the president in India, but rather the Council of Ministers.

The Indian president appoints a Prime Minister to lead the Cabinet and Council of Ministers, as well as act as a Presidential aid. The Council of Ministers, with its executive body being the Cabinet, is made up of the governor of each Indian state. The President also appoints the governor of each state. As per the Indian Constitution; "Governor is the Head of the State and the executive power of the State is vested in him. The Council of Ministers, with the Chief Minister as its head, advises the Governor in the discharge of the executive functions. The Council of the Ministers of a state is collectively responsible to the Legislative Assembly of the State" (India.gov.in, 2005). It is within much of the Indian history and culture that the government was formed. However, Indian values are also a major cultural driver within its society and culture.

Indian values are deeply rooted in relationships, family, friendships, and trust. These values carry over into the business environment as well. When this carries over into business, "most companies tend to be hierarchical, and people expect to work within clearly established lines of authority" (Katz, 2008, p. 5). However, even though the caste social system still exists today, it is not as prevalent as in previous years and does not play a major role in business (Katz, 2008, 1). Additional values that play a major role in the Indian culture are forms of respect. It is very important for them to save face and to have a harmonious relationship than to have a scenario filled with strife and negativity. Other forms of respect include that of holding academia and university degrees to a high regard. Similarly to cultural values are personal traits as well. They go hand-in-hand with cultural values. In India, personal traits that are valued and admired "include friendliness and sociability, flexibility, humility, compassion, resilience, and an ability to find common ground between opposing positions" (Katz, 2008, p. 2). However, there is more to identifying culture than traits and values alone.

Indian art has long been directly related to culture, political viewpoints, opinions, and events of the time. Like many artists, their view of the world and their personal histories and cultures are often reflected in their artwork. The Metropolitan Museum of Art depicts modern Indian art in significant detail:

In the mid-twentieth century, India was a new democratic country carved out of the subcontinent and led by the Indian National Congress. During this nascent period of independence, its citizens sought to define its parameters and understand its reason for being. The cultural sphere was highly politicized. Authors wrote stories and poems that critiqued the way nationalist leaders handled the events leading up to independence and partition of India and Pakistan. Within the burgeoning art scene, artists introduced themselves as modern and secular practitioners. Some were political, while many more were concerned with formal issues. Some incorporated indigenous traditions, while others turned to art practices from outside of India. (Metropolitan, 2010)

Clearly seen, Indian art is important to its culture because it all seems to tie into the modern history of the country; be it relevant issues or politics.

In addition to the aforementioned art forms are the performing arts. Music and movies are a major progressive movement in India. Music genres such as filmi, pop, and hip hop have taken great strides during recent years; as has Bollywood. Bollywood cinema has become a worldwide sensation, and even has festivals and devoted 
television stations in the United States. Regardless of which type of art form, each is a significant portion of their culture that is reflective of the times in which each piece was conceived. Another significant portion of their, or any culture, are traditions.

Cultural traditions are another dynamic that is deeply rooted in a culture's history and value system. Whether traditions are based on historic events, political celebrations, or religious formalities, all are a key element to each culture. For instance, there is a wide array of traditional dance in India, as well as major national sports such like field hockey and cricket. With over 500,000 villages and 17 major languages in India, it is clear that traditions have a major effect on Indian culture. As all government structures, cultural values, and traditional societal dynamics are grouped together, an assessment of cross-cultural behavior patterns begins to form.

\section{CROSS-CULTURAL BEHAVIORAL PATTERNS}

Through significant research, it has been found that there are two types of cultures in the business world, should they be compartmentalized; deal-focused (DF) and relationship focused (RF). According to Richard Gesteland, "deal-focused people are fundamentally task-oriented, while relationship focused folks are more peopleoriented" (Gesteland, 2005, p. 18). When beginning to look at how cultures communicate, it is also important to see contrasts as well.

The United States is, by far, a DF culture. DF cultures are often typically viewed as straightforward, direct, often impatient, and sometimes even aggressive. In contrast, India is strictly an RF culture. India's culture focuses heavily on relationships and relationship building. Even though, the various generations approach relationship building time differently, the process should not be overlooked whatsoever (Gesteland, 2005, p. 130). Each new relationship should be treated, with care and patience. Furthermore, established relationships should continue to be strengthened. To the Indian culture, "building lasting and trusting relationships is...very important," as well as "belonging to a group, conforming to its norms, and maintaining harmony among its members" (Katz, 2008, p. 1). Maintaining harmony takes time.

To maintain harmony, trust has to be built between the parties. Often, the U.S. culture is seen as closed-off and keeps their personal self out of the picture. Indian relationships can only be well-established and grown through quite the opposite personal direction. Relationships in India work bi-directionally. This takes place as both sides of the relationship will have to be willing to open up; speaking about their self, their friends, and their family (Katz, 2008, p.1). DF cultures focused on garnering business relationships from India must understand that Indian culture typically will only work and deal with parties whom they have grown to know and trust. However, through identifying India as an RF culture, there are more cultural traits that can also be discovered.

Being an RF-style culture, indirect approaches to business and personal relationships are often common. Being too direct can hinder the relationship building process. As such, there are several steps that can be taken to begin a lasting relationship in the Indian culture:

1. Arrange for a third-party, person or organization, to introduce you to the desired relationship party; the higher status, the better.

2. It is possible to approach embassy officials to set up introductions. These officials are held in high regard in RF cultures.

3. "Chambers of commerce, trade associations and banks are also potential introducers." (Gesteland, 2008, pp. 23-24)

Clearly seen, relationships are the forefront of business and personal dealings in India. Without a correct approach to relationships, business success and partnerships would be limited. However, another factor lies within the culture as well. Perhaps it is what time the meeting takes place, or how to approach time, in general.

The cultural process of time in India is rather fluid and polychronic, where in the US, schedules are tight and punctuality is rigid; monochronic. In the Indian culture, punctuality is expected, yet the schedules remain rather fluid and open to change as "plans and schedules are contingent on other people and events" (GlobalEdge, 2010, 
India). Depending on the circumstances, the time scheme may be rigid and fluid. In short, the finalized begin-time is important to be punctual, yet one must remain flexible and open to scheduling changes as the meeting date comes closer. It is important to schedule meetings a minimum of four weeks in advance to account for these possibilities (Katz, 2008, p. 3). However, in social situations, it is acceptable to be a few minutes late, as is in the US.

India is a major player in the US marketplace. As of 2007, Gartner market study research indicates that India had the revenue potential equal to $\$ 13.8$ billion USD just due to US outsourcing alone (Cohen, 2007, p. 160). Finding and cultivating lasting business relationships is pertinent and understanding the Indian viewpoint of fluid time is crucial. As relationships are introduced, cultural understanding is increased, and time is understood, the people of the Indian culture must be understood as well.

The culture of India is both expressive and emotionally reserved, but as a whole, more closely toward emotionally reserved. Indian culture is expressive due to the way that people open up and are interested in personal academia, friends, and family. However, it is more so emotionally reserved due to the guarded nature in which emotions are handled. The overall atmosphere of relationship building, business partnership discussions, or negotiations is positive. It is utterly important to "give feedback in a positive and constructive spirit while masking any negative feelings with a smile" (Katz, 2008, p. 2).

"Saving face" is commonplace during discussion. When "face" is lost, the Indian culture views this as destructive to the relationship and sometimes thought of as aggressive and impatient. As an example, it is common for feedback to contain only positive comments and "candid comments and criticism may only be conveyed in private, and often indirectly through a third party" (Katz, 2008, p. 2). Indirect language and gestures are often used in place of enabling a negative response or triggering a negative environment. Furthermore, the simple use of the word "no" may not be used much, if any, in direct conversations. If DF cultures do not understand RF cultures and their complexities, they run the risk of ambiguous and vague understanding of conversation. Furthermore, they run the risk of not being able to articulately comprehend the topics discussed. More of this cultural dynamic can be seen in Geert Hofstede's research as well.

\section{CULTURAL DIMENSIONS IN INDIA: HOFSTEDE'S FINDINGS}

Geert Hofstede's work is known throughout the world due to his extensive research on how cultures interact, both as countries and within organizations as well. Both national and organizational cultures are extremely diverse everywhere. In fact, Hofstede "argues that while business practices (corporate behavior) across companies may look very similar, the underlying national values remain divergent" and that "national cultural differences reside mostly in values and less in practices, while for organizations, the reverse is true" (Schneider \& Barsoux, 2003,p. 75). Through all of his national and organizational culture research, he has identified a certain set of dimensions - power distance (PDI), individualism versus collectivism (IDV), masculinity or achievement orientation versus femininity or nurturing-orientation (MAS), uncertainty avoidance (UAI), and long-term versus short-term orientation (LTO). Each of these dimensions can be tied to Indian culture for a more in-depth look at cultural business dynamics and are referenced in Figure 2.

The power distance dimension quantifies how well a society is willing to accept that power and is not distributed evenly throughout. It is not forced, but driven somewhat by the bottom of society. Hofstede explains that inequality is endorsed by the followers as much as it is by the leaders (Hofstede, 2009). India has received a score of 77 (out of 100) for the power distance dimension, compared to the world average at 56.5 (Hofstede, 2009). This is also the highest ranked of the five dimensions measured for India. In general, this means that it is generally accepted that the unequal distribution of power is commonplace for Indian culture. As previously seen, based on relationships and group needs, individualism versus collectivism is brought forth as well.

Indian culture received a score of 44 for individualism versus collectivism. This shows that collectivism is more of the dominant part of the spectrum. As previously seen, Indian culture is very relationship and group driven. It comes as no surprise that collectivism is the dominant trait of this dimension. What can also be looked at is masculinity (or achievement orientation) versus femininity (or nurturing orientation). 


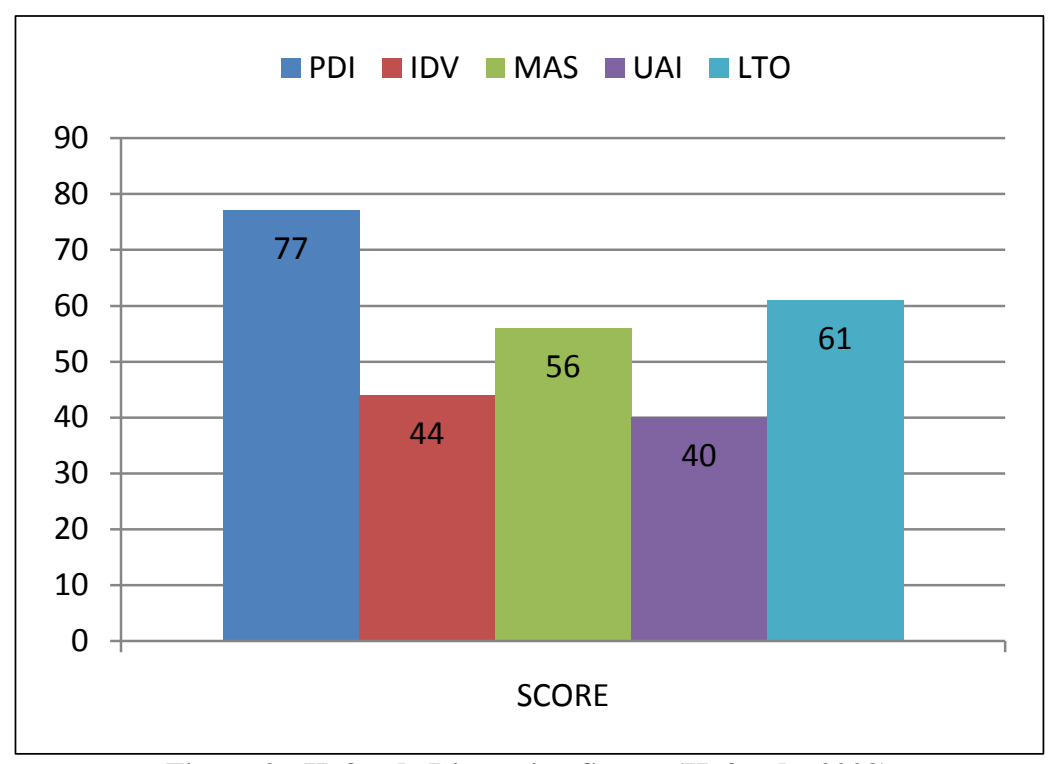

Figure 2: Hofstede Dimension Scores (Hofstede, 2009)

Often misconstrued, these categories do not actually imply gender to any particular subject within this dimension. Actually, each term has a specific purpose. Masculine cultures tend to focus on aggressiveness, directness, boldness, and materialism. Femininity refers more to a nurturing environment, fostered relationships, and more uplifting environments. Through Hofstede's research, it can be seen that India is about on par with the rest of the world, and is about average. The Indian Hofstede score was 56, while the rest of the world was a 51 and as a score gets higher, it indicates a greater gap between the values of males and females (Hofstede, 2009). However, just because one dimension is on par with the rest of the world, does not mean all dimensions follow suit.

The uncertainty avoidance dimension "refers to a society's discomfort with uncertainty, preferring predictability and stability" (Schneider \& Barsoux, 2003, p. 87). In this dimension, India is ranked 40, while the rest of the world is a 65 . This tends to show that the Indian culture prefers stability and structure. Relating to cultural characteristics, this score directly relates to the emotionally reserved and relationship focused cross-cultural behaviors that have been previously mentioned. When combined, it can be seen how negativity and saving face are much preferred to uncomfortable and negative situations. There are benefits to this standpoint and can be seen in the final dimension; long-term versus short-term orientation.

The Hofstede score for the long-term versus short-term orientation dimension was a 61 , where as the rest of the world averages 48. The Indian culture is an RF culture that focuses on relationships. The LTO score of 61 directly corresponds to this RF cultural trait. The building of relationships is not a short-term objective. Relationships are built for mutual benefit and out of trust. A strong effort goes in to relationship building, especially in business, and it carries over into the long-term orientation viewpoint. Even more relative is its symbiosis with negotiations and contracts. In contracts, it is important to remain flexible and make efforts to retain good relationship ties, as contracts are not always followed word for word. The established trust and strong ties will keep the Indian business partner to their word, and should be seen as such. Even greater details on negotiations can still be seen as well.

\section{NEGOTIATION CONSIDERATIONS}

During negotiations, it is important to keep in mind that India is an RF culture; relationships and harmony are at the forefront. It should also be mentioned that as the Indian economy becomes more integrated or merged with Western economies then it might be anticipated that the tensions, between personal, espoused, values and those required of their managers by companies operating in a global context, would also become greater (Fisher et. al., 2001). With the potential of increased occurrence of harmony of the relationship held in high regard, even greater importance is placed upon knowing how Indian culture functions. 
In business, Indians are fairly competitive negotiators. However, the approach to negotiations and contracts works in two directions. Both parties are expected to understand their role in negotiating and they are expected to act in accordance to meet in agreement. It should be mentioned that Indians "expect long-term commitments from their business partners and will focus mostly on long-term benefits" (Katz, 2008, p. 4). This is another example of how relationships are up front in the RF culture and these cannot be built on a foundation without trust.

In negotiations, the relationship has generally already been built, but it is important to still approach the table with an open mind and be willing to discuss conversational issues. This may indicate a relatively slower negotiation pace, which is generally true. One can expect negotiations to be "slow and protracted" but if "one side appears to be hiding information," then negotiations may start to crumble (Katz, 2008, p. 4). Keeping an open mind in negotiations will prepare a potential DF business partner for finer details.

Indians will expect a lot from the business partners, but then again, they typically are lenient as well. In the Indian RF business culture, many take pride in the art of negotiating and asking for reciprocity of one's own leniency in negotiating is tolerated. There may be a lot of back-and-forth during negotiations and it may be a drawnout process. Patience is a key ingredient to negotiating in India and helping to keep harmony going is a major positive-progressive factor. Even then, there are several warnings to look out for in the negotiation process.

Without patience, Indians may sense impatience and anger, possibly detracting the negotiation process as well. Furthermore, one should "not disagree publicly with members of your negotiating team" since this detracts from the harmonic environment (Kwintessential, 2010, India). Also, "deceptive techniques are frequently used" and "corruption and bribery are quite common in India's public and private sectors" (Katz, 2008, p. 5). These are factors that also must be considered when approaching the negotiation table. One should not approach with a team of lawyers, though. Indians respect the fact that in other cultures bribery is viewed differently. They are open to listening to a company's policies but might be turned off in the negotiation process if they sense that they are being taught a moral lesson (Katz, 2008, p. 5). Bringing a team of lawyers to the table will give Indians the impression that they cannot be trusted, so negotiations may be very difficult, given this would disrupt the RF harmonic environment. Based on these negotiation dynamics, a set of recommendations can be derived.

Employees and customers in different cultures also process verbal and nonverbal information differently. For example, it is important to differentiate between the "low-context" and "high-context" cultures. In low-context cultures such as the United States, words carry most of the information in communications. The message needs to be explicit and detailed because each party will rely almost solely on the information. Generally, Western cultures tend to gravitate toward low-context communications, while Eastern and Southern cultures tend to use high-context communication. In the high-context cultures such as India, communications are less explicit and detailed. Instead, more information is contained in factors surrounding the context of the communications (e.g., background, associations and basic values of the party). Personal relationships, therefore, tend to play a more critical role in highcontext cultures, since the message is embedded in face-to-face body language as well as perceived commonalities. In fact, much of the sales literature confirms that, in high-context cultures, the salespersons themselves have as much, if not more, importance than a formal analysis of product benefits. So the negotiators themselves must first establish their identity and character in order to build trust with their counterparts (Mujtaba, 2007, p. 199).

Negotiators should always open the negotiation by stressing mutual benefits to all parties involved, being clear and positive, implying flexibility, creating interest in the dialogue, demonstrating confidence and trust, and promoting goodwill. These are the imperatives of successful negotiations with Indians and others in a business arena. Furthermore, Mujtaba (2007, p. 211) recommends that it is best to focus on interests, not demands; keep in mind that demands are what you want and interests are why you want them. The bottom-line is to focus on what is fair for each party; keep in mind that emphasizing fairness can allow and encourage both parties to effectively negotiate and eventually agree on a satisfactory solution. While there can be many processes to a negotiation model, it is best to simplify all the steps into as few as possible so that it can be easily remembered and practiced. According to Mujtaba (2007, p. 212), the main steps to a negotiation can be simplified under four categories which are: (1)-Initiating or pre-planning; (2)-Negotiating; (3)-Closing; and (4)-Maintaining the relationship and renegotiating if necessary. From a practical perspective, an effective model in a relationship-focused culture emphasizes a win-win objective with a focus on the creation of a long-term relationship, trust and interdependency, 
and this is especially important in high-context cultures. Long-term relationships and effective networks require maintaining a high level of trust among all parties.

\section{RECOMMENDATIONS}

The RF culture in India is hyper-critical to understand when entering negotiations. Relationships are seen as a long-term investment and one must approach all sides with an open mind. Furthermore, there should also be a process of due diligence complete before approaching the negotiation and relationship-building process. Spending the time to learn about Indian culture, its local customs, and its business protocol and etiquette are highly important. It is recommended that when in negotiations, one fall in line with this business etiquette. For instance, dress is business conservative for both men and women. Previously mentioned, academia is highly respected, so titles in front of names are critical as well (Kwintessential, 2010, India). All of these details can help lay out a plan on how to approach the bargaining and decision-making modes.

Previously mentioned, keeping an open mind is important. It is recommended that respect be given for the time needed for decision-making to take place. Often, the most senior person involved in the deal is who will be making the decisions. Time may be needed for these decisions to be reached. These recommendations are rules of business for all expatriates operating in India or other foreign locations. Mujtaba emphasizes that:

With the rise in global business opportunities, more and more companies find it imperative to expand overseas. But to the surprise of many, deal signing becomes as much a matter of cultural connection as legal conformity. In fact, research in national culture is confirming that partnering across foreign entities requires far more than governance mechanisms. Nations that are inherently sociable in their business dealings, for example, rely more on relational norms than contract signings. This may seem a naïve and vulnerable approach to conducting business, but cultural connection is a reality throughout most of Latin America, Asia, the Middle East and Southern Europe. As borders expand to accommodate these partners, sensitivity to their cultural expectations becomes paramount to relationship building (Mujtaba, 2007, p. 194).

\section{SUMMARY}

By focusing on cultural and behavioral dynamics of Indian culture, a greater chance of success in relationship-building and business partner opportunities can be solidified. Great respect must be given to the situation, as well as all cultures involved. India is a country of great history and cultural tradition that is increasingly becoming a major player in the world economy. Its large population and focus on academia will continue to propel it into the future as a key global business stakeholder. Much of its corporations are heavily globalized already. Learning their culture and how to build lasting relationships with them will be a key ideal to develop for increased and mutually-beneficial business opportunities.

\section{DISCUSSION QUESTIONS}

1. It is mentioned that cross-cultural leadership is a key to formulating successful relationships in India. Several steps are mentioned previously. What are some additional steps that organizational leadership can take to prepare for this relationship building process? Explain why these would be successful.

2. Many organizations in the United States seem to be going toward a flattened, less-hierarchical style of structure. However, Indian organizations tend to be doing just the opposite due to their societal values and cultural drivers. In both cases, this seems to be working so far. What type of culture is your background, DF or RF? Furthermore, do you see your culture's organizations following a similar pattern? Explain.

3. How could an organization breaking into the globalized marketplace train its traditionally DF-style managers to work well with Indian RF-style organizations?

4. If a team of executives from a US-based corporation are working on a partnership agreement with an Indian firm, how could this team prepare and sharpen their observational skills to cope with indirect language, gestures, disuse of "No"? Also, how could this team dissect purely positive comments and feedback to get a detailed understanding of what is expected? 
5. Hofstede's research categorizes one dimensional view by comparing masculinity versus femininity. Since these are often misconstrued as gender characteristics, what would a better classification be to help a group of managers understand the topic?

6. If a US-based corporation wants to approach an Indian company already well-established in the US, should it take a traditional business approach that it uses for normal business deals? Why or why not?

7. As mentioned, the United States is a DF culture. How could the executive board of a US-based organization gain the trust of its stakeholders when entering into a partnership with an Indian organization? How may the long-term focus affect the feelings of the shareholders that may be used to short-term results?

8. It is commonplace in the US to use a team of attorneys to safeguard a business deal or transaction. However, this approach would not be trusted by an Indian organization and the deal would fall through. How could a US company still safeguard itself without having to bring a team of lawyers to the table? Is this possible? Why or why not?

\section{AUTHOR INFORMATION}

Andrew H. Clem is a graduate researcher in leadership at Nova Southeastern University's H. Wayne Huizenga School of Business and Entrepreneurship. Always having a passion for the environment and technology, his goal during his undergraduate degree was to pursue a career in combining these interests. Clem graduated from the University of Kentucky with a Bachelor of Science in Forestry. He continued to pursue his combined interests while working through a series of forestry consulting, infrastructure, and GPS mapping projects. Clem is currently a fulltime GIS Specialist and task manager with the engineering firm, CDM. Upon completion of his graduate research, he plans to continue to apply technological solutions to environmental needs. Clem also intends to aggressively lead and develop a positive synergy between the environmental business sector and environmental issues. Andrew's research areas include management, leadership, and knowledge management application

Bahaudin G. Mujtaba, D.B.A., is an Associate Professor of Management, International Management, and Human Resources at Nova Southeastern University's H. Wayne Huizenga School of Business and Entrepreneurship. Bahaudin has served as manager, trainer, and management development specialist in the corporate arena as well as a director, department chair and faculty member in academia. His areas of research are management, leadership and management history, and international management. Bahaudin can be reached at: mujtaba@nova.edu

\section{REFERENCES}

1. Fisher, C. M., Shirole, R., and Bhupatkar, A. P, (2001). Ethical stances in Indian Management culture. Personnel Review, 30(5/6), 694-711. Retrieved August 10, 2010, from ABI/INFORM Global. (Document ID: 268855421).

2. Gesteland, R. R., (2005). Cross-Cultural Business Behavior: Negotiating, Selling, Sourcing and Managing Across Cultures. Copenhagen, Denmark: Copenhagen Business School Press. GlobalEdge. (2010). India. Accessed on August 3, 2010 at http://globaledge.msu.edu/countries/india/

3. Hofstede, G., (2009). Geert Hofstede Cultural Dimensions (India). Accessed on August 3, 2010 at http://www.geert-hofstede.com/hofstede india.shtml

4. India.gov.in., (2005). Constitution of India. Accessed on August 15, 2010 at http://india.gov.in/govt/constitutions_india.php

5. Katz, L., (2008). Negotiating International Business - India. Negotiating International Business: The Negotiator's Reference Guide to 50 Countries Around the World. Charleston, South Carolina: BookSurge Publishing.

6. Kwintessential. (2010). India - Language, Culture, Customs, and Etiquette. Accessed on June 24, 2010 at http://www.kwintessential.co.uk/resources/global etiquette/india-country-profile.html

7. Metropolitan Museum of Art. (2010). Modern Art in India. Heilbrunn Timeline if Art History. Accessed on August 15, 2010 at http://www.metmuseum.org/toah/hd/mind/hd_mind.htm

8. Mujtaba, B. G. (2007). Cross Cultural Management and Negotiation Practices. ILEAD Academy Publications; Florida, United States.

9. Schneider, S.C., and Barsoux, J., (2003). Managing Across Cultures. Harlow, Essex, England, United Kingdom: Pearson Education Limited. 